\title{
C-rel : un nouvel oncogène impliqué dans l'apoptose
}

Le proto-oncogène c-rel code pour un facteur de transcription qui présente des analogies structurelles et fonctionnelles avec d'autres facteurs de transcription dont les plus connus sont le facteur quasi-ubiquitaire NF-KB et la protéine morphogène Dorsal de drosophile. Les protéines de cette famille sont constituées de deux domaines: un domaine $\mathrm{N}$ terminal fortement conservé appelé le rel homology domain et un domaine C-terminal totalement divergent parmi les différents membres de la famille. Ces facteurs de transcription s'associent en homo ou hétérodimères par l'intermédiaire de leur domaine $\mathrm{N}$-terminal et se fixent sur l'ADN au niveau de séquences spécifiques appelées sites $\kappa \mathrm{B}$. La transcription des gènes situés en aval est alors activée plus ou moins intensément, voire même réprimée, selon le dimère considéré. C'est essentiellement la nature du domaine $\mathrm{C}$ terminal qui détermine les différences de capacités transactivatrices de ces différentes protéines.

Lorsque les cellules sont stimulées par certains facteurs (cytokines, esters de phorbol, stress oxydatif...), les facteurs de transcription de la famille Rel peuvent être activés au niveau transcriptionnel mais également au niveau post-traductionnel. En effet, dans la cellule, ces facteurs existent constitutivement sous forme d'un complexe multiprotéique inactif, car retenu dans le cytoplasme

pour inhibitory protein). Sous l'effet du stimulus, I $\mathrm{k}$ est phosphorylée ou dégradée, ce qui libère le facteur de transcription et permet sa migration vers le noyau (pour revue voir $m / s, n^{\circ} 1$, vol. 7, p. 67 [1]).

$\mathrm{Si}$, comme on le voit, la fonction biochimique des protéines de la famille Rel est assez bien connue, leur fonction biologique reste à établir. Chez le poulet, une étude par Northern blot de la répartition tissulaire des $\mathrm{ARNm}$ avait montré que $c$ rel s'exprime essentiellement dans les organes hématopoiétiques (thymus, bourse de Fabricius, rate) [2]. Le rétrovirus Rev-T qui porte l'oncogène v-rel est connu pour induire chez le jeune oiseau des lymphomes mortels [3]. Ces deux observations incitent à penser que la protéine cRel pourrait être impliquée dans les mécanismes de différenciation des cellules de la lignée lymphoïde. Au laboratoire d'oncologie moléculaire de l'Institut Pasteur de Lille, nous avons choisi d'explorer une deuxième possibilité basée sur l'homologie entre c-Rel et Dorsal : cRel a-t-elle, comme Dorsal, un rôle dans l'établissement de l'axe de polarité dorso-ventral de l'embryon précoce ? Pour aborder cette question, nous avons étudié par hybridation in situ l'expression de c-rel dans l'embryon de poulet, des premiers stades de développement intra-utérin jusqu'au stade 4 jours d'incubation. Les signaux obtenus indiquent que c-rel s'exprime dans tous les tissus à un niveau faible mais significatif, sauf dans quelques cellules, généralement isolées, où son expression est beaucoup plus forte. Ces cellules, surtout observées aux stades 3 et 4 jours d'incubation, sont rencontrées dans une grande variété de tissus: tube neural, ganglions nerveux, crêtes neurales, gonades, fentes branchiales, chorde, mésenchyme... L'observation à fort grossissement après coloration avec un intercalant de l'ADN (Hoechst 33258) a montré que ces cellules avaient un noyau généralement fragmenté et une chromatine condensée. Cette morphologie est typique de cellules subissant le phénomène d'apoptose, un type de mort cellulaire programmée. Ces résultats ont permis de réorienter les hypothèses de départ vers un rôle potentiel de c-rel dans l'apoptose. Pour confirmer les observations faites sur le jeune embryon, l'expression de c-rel a été analysée lors de la formation du bourgeon de membre, un processus de morphogenèse où la mort cellulaire programmée intervient, entre autres, dans la séparation des doigts. A nouveau, nous avons observé une forte expression de c-rel dans les cellules en apoptose du mésenchyme interdigital (figure 1) [4].

Pour aller au-delà de ces observations et pour essayer d'établir une relation de cause à effet entre l'expression de c-rel et l'évolution de la cellule vers la mort, l'équipe de P. Enrietto à l'université de New 

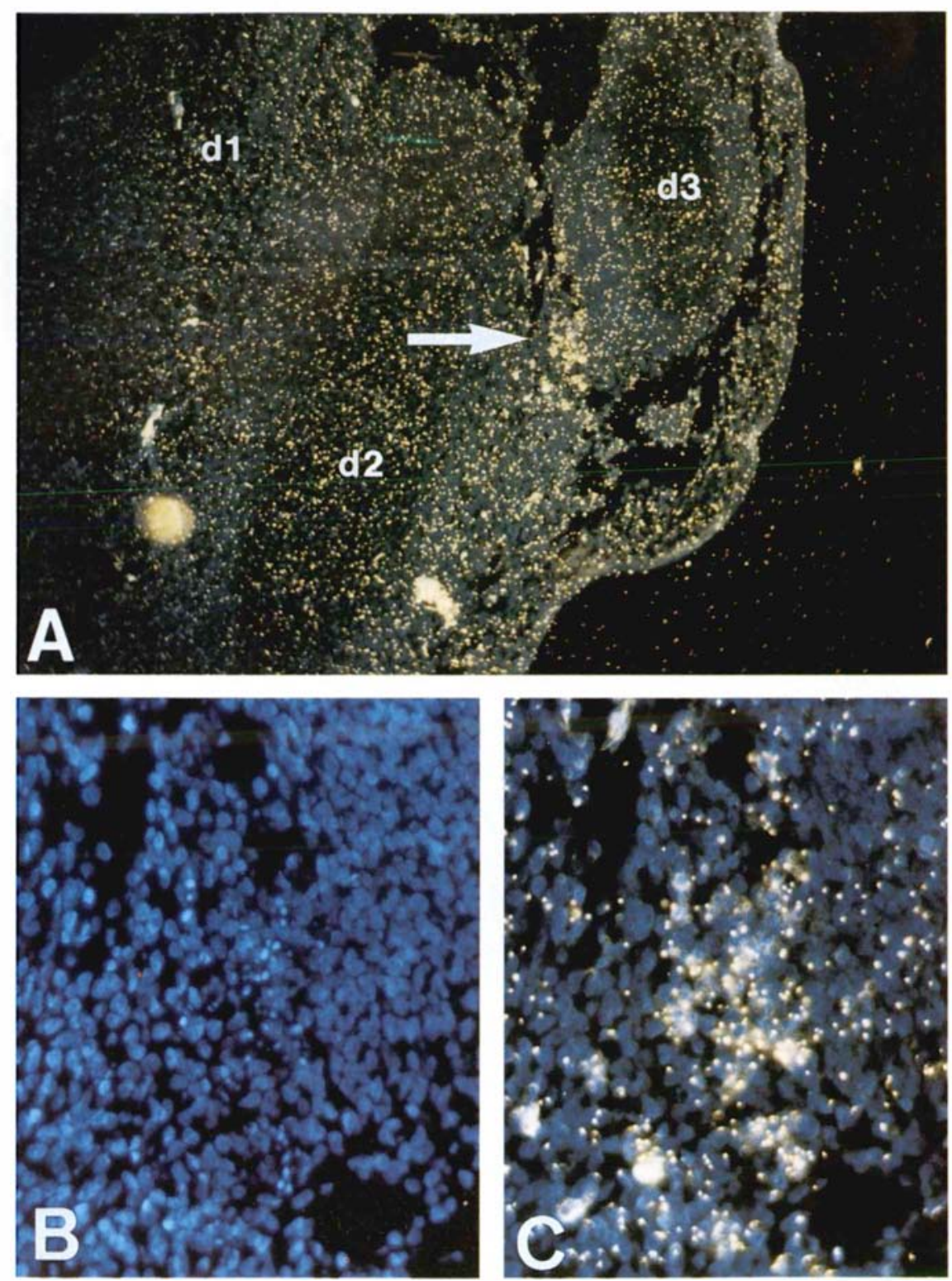

Figure 1. A. Coupe transversale dans une patte d'embryon de poulet à 7 jours d'incubation hybridée avec une sonde ARN anti-c-rel et colorée au Hoechst. Les grains d'argent (flèche) révèlent la présence d'ARNm rel dans le mésenchyme interdigital (d1, d2, $d 3$ indiquent les trois doigts visibles sur cette coupe.). B et C. Grossissement de la zone marquée. $L$ 'observation en Hoechst (B) permet de voir que les cellules qui expriment C-rel (C) sont apoptotiques (noyau fragmenté et chromatine très brillante car condensée).

York, Stony Brook, a surexprimé crel dans des cellules en culture et analysé les conséquences de cette surexpression sur la capacité des cellules à mourir par apoptose. Pour ce faire, des fibroblastes embryonnaires et des cellules de moelle osseuse adulte de poulet ont été infectés par un rétrovirus (RCAS) dans lequel le gène c-rel a été inséré. La surexpression de c-rel entraîne une transformation de la morphologie des fibroblastes et augmente la durée de vie de la culture qui passe de deux mois (environ 20 passages) à six mois (environ 60 passages). Au contraire, les cellules de moelle osseuse surexprimant c-rel meurent rapidement et massivement par un processus très voisin de l'apoptose [4]. L'ensemble de ces résultats suggère que c-rel pourrait avoir un rôle dans le déclenchement ou le déroulement de l'apoptose. Ciependant, comme récemment discuté dans médecine/sciences [5], ils indiquent aussi que la fonction de c-rel pourrait changer selon le type cellulaire, le contexte extracellulaire (cytokines, matrice extracellulaire, interactions cellule-cellule) ou le stade de développement et conduire à des situations apparemment aussi différentes que la mort ou la transformation et l'immortalisation partielle.

C.A.

1. Blank V, Kourilsky P, Israel A. NF-kappa $B$ and related proteins: Rel/dorsal homologies meet ankyrin-like repeats. Trends Biochem Si $1992 ; 17$ : 135-40.

2. Moore BE, Bose HR. Expression of the $c$ $r e l$ and $c-m y c$ protooncogenes in avian tissues. Oncogene 1989; 4: 845-52.

3. Barth CF, Ewert DL, Olson WC, Humphries EH. Reticuloendotheliosis virus REVT (REV-A)-induced neoplasia: development of tumors within the T-lymphoid and myeloid lineages. / Virol 1990; 64: 6054-62.

4. Abbadie C, Kabrun N, Bouali F, Smardova J, Stéhelin D, Vandenbunder B, Enrietto P. High levels of c-rel expression are associated with programmed cell death in the develo ping avian embryo and in bone marrow cells in vitro. Cell 1993; 75 : 899-912.

5. Kahn A, Briand P. L'apoptose, une mort programmée ou une diffërenciation avortée? médecine/sciences $1993 ; 9$ : 663-5.
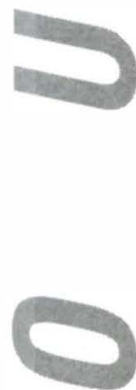